\title{
How the classification of von \\ Willebrand Disease can guide therapy
}

\section{Michael Laffan}

In a recent editorial published in Haemophilia, Millar asks 'Why and how do we classify von Willebrand disease?' [1]. This may seem like a philosophical question, but two case reports in this edition of The Journal of Haemophilia Practice illustrate good practical answers to both parts of the question.

Von Willebrand factor (VWF) is a large plasma glycoprotein with a dual role in haemostasis. First, it performs an adhesive function in primary haemostasis to capture platelets on the extracellular matrix after damage to the vessel wall. To perform this function adequately, VWF requires a large multimeric structure and intact binding sites for both collagen and platelets. Second, it protects coagulation factor VIII (FVIII) from premature clearance and increases its half-life in the circulation. Although an intact FVIII binding site on VWF is required, this function is not dependent on VWF size. The multiple binding sites, assembly into large multimers and requirement for shear stress for optimum function make VWF a complicated molecule to assess in the laboratory. Moreover, these multiple interactions, multimeric structure and the simple fact that the VWF gene is very large mean that there are many different ways in which the VWF molecule can malfunction. These different forms of VWF deficiency form the basis of the Von Willebrand disease (VWD) classification. A discussion of these problems and a practical approach to classification can be found in the latest UKHCDO guidelines [2].

Rashid et al [3] report two families with the same defect in their VWF molecules, which makes them unable to bind to collagen. VWD due to defective collagen binding is a relatively new addition to the VWD classification but as pointed out in Carolyn Millar's editorial, it is only by the grouping of patients with the same pattern of findings that we can begin to understand the nature of the disorder [1].

The reason why collagen-binding defects have been reported relatively rarely is not clear. It may be in part that collagen binding assays have been used infrequently in the past but considering all the reported cases together we can see that it may be because the phenotype is relatively mild, even when binding to type III collagen is almost completely

Michael A Laffan, professor and consultant, Centre for Haematology, Hammersmith Hospital, Imperial College London, London, UK.

E-mail: m.laffan@imperial.ac.uk

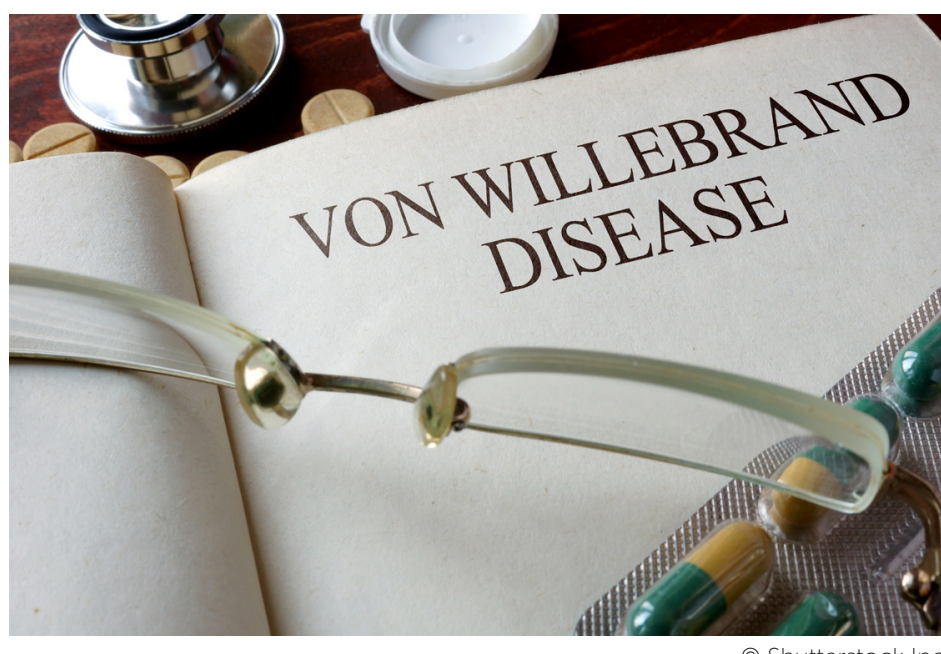

(c) Shutterstock Inc.

abolished. This in turn may be because the VWF molecule has two potential collagen binding sites and it would be extremely unusual for both to contain mutations. Like other $2 \mathrm{M}$ forms, the inheritance appears to be autosomal dominant which fits with the dependence of collagen binding on high molecular weight multimers. Collagen binding assays are now recommended as part of the standard investigations for VWD [2]. This report also illustrates how once the defect has been correctly identified, it allows assessment of the response to desmopressin and an effective treatment plan to be drawn up.

In the second article, Fosbury et al discuss the de novo and unexpected presentation of VWD in a neonate [4]. In this case analysis of the clinical picture led rapidly to the diagnosis of a bleeding disorder and makes the important point that a low FVIII is not always the result of haemophilia.

As noted above, FVIII relies on VWF for its survival in the circulation and when insufficient VWF is present the FVIII level will fall giving a superficial resemblance to haemophilia. In an emergency such as this it is important to begin replacement therapy before the diagnosis is known, at which point specific factor concentrates can be used. The blood levels at discharge suggest that he has type 3 VWD, which is the most severe form and characterised by a complete absence of VWF.

From a practical point of view the classification for patients with very low levels is not important for treatment because 
they will almost certainly have an inadequate response to desmopressin and will invariably require VWF replacement therapy for all but the smallest of bleeds. It will, however, have implications for genetic counselling because type 3 has a recessive pattern of inheritance in contrast to the dominant pattern of type 1 and most type 2 forms.

As pointed out in the review, the classification system serves a number of purposes:

- By grouping patients with similar laboratory findings together, it allows us to identify distinct forms of the disease and learn more about the structure, function and clinical behaviour of VWD.

- It can help guide us to appropriate therapy even though this will always in the end be an empirical issue requiring assessment of individual patients.

- By identifying patterns, it allows us to make useful predictions of future problems for families.

\section{Disclosures}

The authors have advised that there are no interests that might be perceived as posing a conflict or bias.

This is an Open Access article distributed under the terms of the Creative Commons Attribution License (http://creativecommons.org/licenses/ by/2.0), which permits unrestricted use, distribution, and reproduction in any medium, provided the original work is properly cited.

\section{References}

1. Millar C. Why and how do we classify von Willebrand disease? Haemophilia 2015; 21(4): 407-10. doi: 10.1111/hae.12725.

2. Laffan MA, Lester W, O'Donnell JS, Will A, Tait RC, Goodeve A, Millar CM, Keeling DM. The diagnosis and management of von Willebrand disease: a United Kingdom Haemophilia Centre Doctors Organization guideline approved by the British Committee for Standards in Haematology. $\mathrm{Br} \mathrm{J}$ Haematol 2014; 167(4): 453-65. doi: 10.1111/bjh.13064.

3. Rashid S, Bignell P, Keeling D, Curry N. Management of an uncommon form of type 2M VWD: a single centre experience. J Haem Pract 2016; 3(1). doi: $10.17225 /$ jhp00065

4. Fosbury E, Blumberg R, Liesner R, Sibson K. Lessons from a neonate with unusual bleeding. J Haem Pract 2016; 3(1). doi: 10.17225/jhp00064

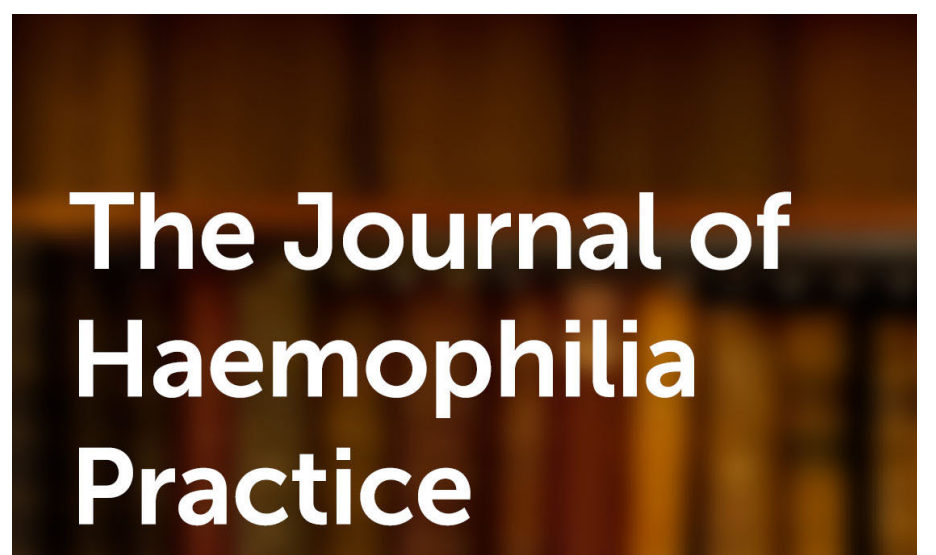

An open-access journal for

sharing

experience in

the care of

people with

bleeding

disorders

www.haemjournal.com 